\title{
Enteric duplication in children: clinical presentation and outcome
}

\author{
Naima $\underline{\text { Rasool }}^{1}$, FCPS, FRCS, Chaudhry Aqeel $\underline{\text { Safdar }}^{1}$, FRCS, Asrar $\underline{\text { Ahmad }}^{1}$, FCPS, Shehla $\underline{K a n w a l}^{1}$, MBBS
}

INTRODUCTION Enteric duplication (ED) is an anomaly with varied presentations and possible involvement of the alimentary tract. Once diagnosed, resection of the lesion and the involved part of the gut is usually required. The aim of this study was to evaluate the clinical presentations, diagnostic investigations, management and outcomes of patients with ED.

METHODS This was a descriptive case study conducted at the Department of Paediatric Surgery, Military Hospital, Rawalpindi, Pakistan, from January 2005 to January 2011. The medical records of all patients diagnosed with ED were retrospectively analysed with respect to age, presentation, investigations, site and type of lesion, surgical procedures, histological findings and complications.

RESULTS A total of nine patients were managed during the study period. The patients' ages ranged from three months to five years. Four out of nine EDs were rectal duplications. Three EDs were of the cystic type, five were of the tubular type and one was a complex mixed anomaly. Patients presented with varied symptoms, with the two most common being the presence of an abdominal mass and bleeding per rectum. Diagnosis was mainly achieved based on magnetic resonance imaging and computed tomography, although Meckel's scan provided accurate diagnosis in three of the nine patients. All the cysts were resected without any major complications, and patients were event-free during the five-year follow-up.

CONCLUSION EDs should be kept in mind when examining patients with an abdominal mass and bleeding per rectum. Meckel's scan can provide accurate diagnosis of EDs with bleeding. Prompt diagnosis and management results in satisfactory outcomes.

Keywords: gastrointestinal diseases, gastrointestinal haemorrhage

\section{INTRODUCTION}

Gastrointestinal $(\mathrm{Gl})$ duplications are rare anomalies that require a high index of suspicion during clinical examination. Their clinical presentations vary according to the site of duplication. The ileum is the most common region involved. Abdominal symptoms may include the presence of pain, masses and bleeding per rectum, or present acutely as intussusceptions, volvulus or intestinal obstruction. ${ }^{(1,2)}$ Duplications may be incidentally encountered during surgery for other medical conditions. Although ultrasonography, computed tomography (CT), magnetic resonance (MR) imaging and laparoscopy are the main diagnostic tools, ${ }^{(2)}$ radioisotope imaging may be useful for identifing bleeds in the heterotopic gastric mucosa.

Enteric duplication (ED) may be cystic, tubular, or very rarely, complex mixed. It usually communicates with the gut but may occasionally be isolated. Duplication of the entire GI tract has previously been reported. ${ }^{(3)}$ Malignancy has also been reported in a female infant with a duplicated gut.(1) Treatment options depend on the type of cyst. Excision of the lesion with minimal resection of the involved segment of the gut is advised, although partial resection and stripping of the residual mucosa are acceptable alternatives, especially for the tubular variety or when the cyst cannot be completely excised. ${ }^{(4)}$ The aim of this study was to evaluate the clinical presentations, pathologies, diagnostic investigations, management strategies and outcomes of patients with ED.

\section{METHODS}

This retrospective descriptive study was conducted at the Department of Paediatric Surgery, Military Hospital, Rawalpindi, Pakistan, from January 2005 to January 2011. All patients diagnosed with ED and managed during the study period were enrolled in the study. Institutional approval and written consent for the use of patients' data and pictures were obtained for the study. Data collected included variables such as age, clinical symptoms, diagnostic modalities used, types of duplication, surgical procedures performed, complications and histological findings. Results were analysed using descriptive statistics.

\section{RESULTS}

Of the nine patients who presented with ED, nearly two-thirds were infants (age range 3 months -5 years). Seven (77.8\%) were male and two $(22.2 \%)$ were female. The presenting symptoms were varied, with the most common being abdominal mass and bleeding per rectum. Descriptions of the patients' age and gender, clinical features, main investigations, types and sites of cysts, surgical procedures performed and complications observed are

${ }^{1}$ Department of Paediatric Surgery, Military Hospital, Rawalpindi, Pakistan

Correspondence: Major Naima Rasool, Consultant Paediatric Surgeon, Department of Paediatric Surgery, Military Hospital, The Mall, Rawalpindi 54600, Pakistan. dr_naima_r@yahoo.com 
Table I. Characteristics of patients $(n=9)$.

\begin{tabular}{|c|c|c|c|c|c|c|c|}
\hline Patient & $\begin{array}{l}\text { Age/ } \\
\text { gender }\end{array}$ & $\begin{array}{l}\text { Presenting } \\
\text { symptom }\end{array}$ & $\begin{array}{l}\text { Diagnostic } \\
\text { investigation }\end{array}$ & $\begin{array}{l}\text { Type of } \\
\text { lesion }\end{array}$ & $\begin{array}{l}\text { Site of } \\
\text { lesion }\end{array}$ & $\begin{array}{l}\text { Surgical } \\
\text { procedure }\end{array}$ & Complication \\
\hline 1 & $\begin{array}{l}3 \text { mths/ } \\
\text { male }\end{array}$ & $\begin{array}{l}\text { Urine retention, } \\
\text { abdominal mass }\end{array}$ & MR imaging & Cystic & Rectum & Excision & $\begin{array}{l}\text { Transient } \\
\text { retention of urine }\end{array}$ \\
\hline 2 & $\begin{array}{l}4 \text { mths/ } \\
\text { female }\end{array}$ & Bleeding per rectum & $\begin{array}{l}\text { Technetium-99m } \\
\text { imaging }\end{array}$ & Tubular & Ileum & Excision & None \\
\hline 3 & $\begin{array}{l}5 \text { mths/ } \\
\text { male }\end{array}$ & $\begin{array}{l}\text { Urine retention, } \\
\text { lower abdominal } \\
\text { mass }\end{array}$ & $\mathrm{CT}$, MR imaging & Cystic & Rectum & Excision & None \\
\hline 4 & $\begin{array}{l}5 \text { mths/ } \\
\text { female }\end{array}$ & Perineal swelling & MR imaging & Tubular & Rectum & Excision & Wound infection \\
\hline 5 & $\begin{array}{l}6 \text { mths/ } \\
\text { male }\end{array}$ & Bleeding per rectum & $\begin{array}{l}\text { CT, Meckel's } \\
\text { scan }\end{array}$ & Complex & $\begin{array}{l}\text { Jejunoileal } \\
\text { region }\end{array}$ & $\begin{array}{l}\text { Excision, } \\
\text { marsupialisation }\end{array}$ & None \\
\hline 6 & $\begin{array}{l}1 \mathrm{yr} / \\
\text { male }\end{array}$ & $\begin{array}{l}\text { Abdominal mass, } \\
\text { pain, vomiting }\end{array}$ & Ultrasonography & Cystic & Ileum & Excision & None \\
\hline 7 & $\begin{array}{l}1.5 \mathrm{yrs} / \\
\text { male }\end{array}$ & Perineal abscess & MR imaging & Tubular & Rectum & Excision & Wound infection \\
\hline 8 & $\begin{array}{l}3 \mathrm{yrs} / \\
\text { male }\end{array}$ & $\begin{array}{l}\text { Huge abdominal } \\
\text { mass, vomiting }\end{array}$ & CT & Tubular & $\begin{array}{l}\text { Jejunoileal } \\
\text { region }\end{array}$ & Excision & None \\
\hline 9 & $\begin{array}{l}5 \mathrm{yrs} / \\
\text { male }\end{array}$ & Bleeding per rectum & Meckel's scan & Tubular & Ileum & Excision & None \\
\hline
\end{tabular}

CT: computed tomography; MR: magnetic resonance

presented in Table I. A total of four out of nine patients had rectal duplications, and a perineal mass was noted in one (11.1\%) patient. One patient had infected wound discharge following drainage of a perineal abscess, while penoscrotal hypospadias was present in another.

Ultrasonography suggested a diagnosis of ileal duplication cyst in one patient. CT and MR imaging performed in the three patients with abdominal mass demonstrated a duplication cyst, with differential diagnoses of mesenteric cyst, anterior sacral meningocele and lymphangioma. In one patient, MR imaging was suggestive of recurrent perineal abscess but could not identify the underlying duplication cyst. However, Meckel's scan, which was positive for aberrant mucosa in all three patients with bleeding, suggested duplication. Five patients were operated on using conventional upper transverse laparotomy incision, while lower abdominal transverse incision was used on two patients. Chevron and cruciate incisions were employed in the surgical procedures of cases with perineal mass and residual perineal abscess, respectively. Different types of duplication cysts (ileal cystic, $\mathrm{n}=1$; ileal tubular, $\mathrm{n}=3$; rectal tubular, $\mathrm{n}=2$, rectal cystic, $\mathrm{n}=2$; complex of mixed tubular and jejunoileal cystic, $n=1$ [Fig. 1]) were encountered. Resection of the cyst was performed in all patients; the largest excised portion was approximately $13 \mathrm{~cm}$ of the ileum. All resected segments were sent for histopathological analysis. The presence of heterotopic gastric mucosa was confirmed in three patients with rectal bleeding. One patient required bladder catheterisation over a period of two weeks due to postoperative development of a transient neurogenic bladder, but recovered without further intervention. Two patients had a superficial wound infection, but all other patients had an uneventful postoperative course.

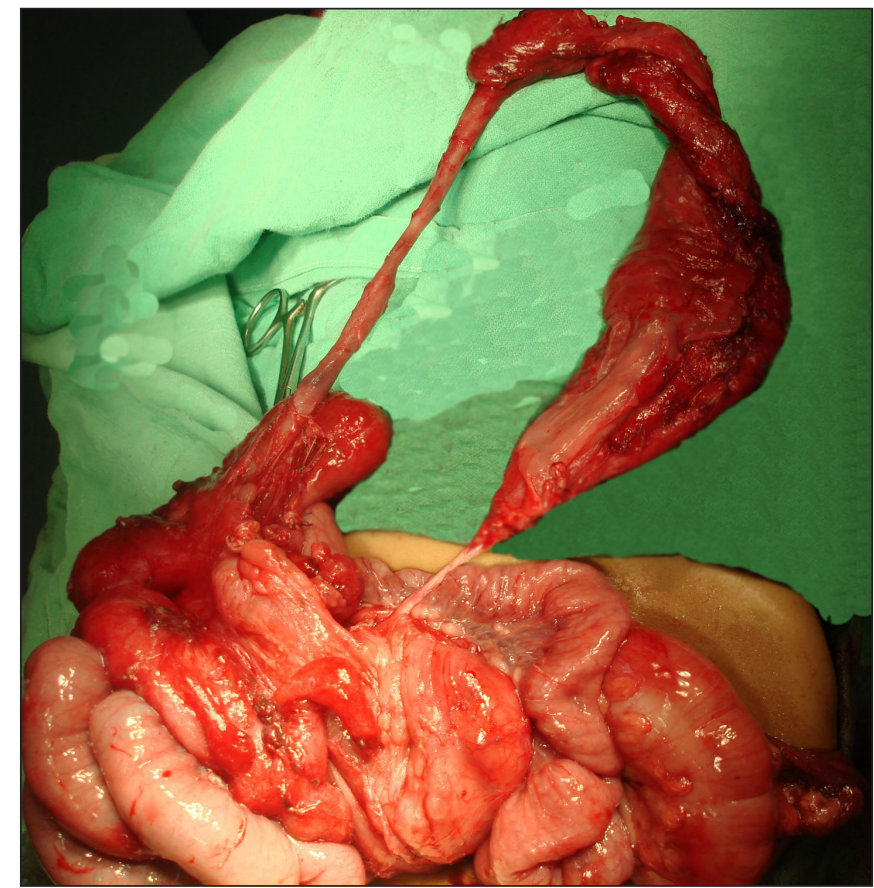

Fig. 1 Intraoperative photograph shows a complex enteric duplication cyst involving interconnected multiple tubular and cystic duplications.

\section{DISCUSSION}

EDs are rare surgical anomalies that are potentially life threatening. ${ }^{(3)}$ While there is no consensus on the exact embryological origin of EDs, the split notochord theory is widely accepted. Other theories such as incomplete twinning, phylogenetic reversal, persistent embryonic diverticula and dysvacuolation have also been suggested. ${ }^{(1)}$ Lipsett et al hypothesised that nests of trapped endodermal cells of the developing gut or persistent epithelial buds within the wall may be a cause of ED. ${ }^{(2)}$ Although $\mathrm{ED}$ may present at any age, a majority 
of patients present during infancy. ${ }^{(5)}$ Accordingly, nearly twothirds of our patients were infants. Presenting symptoms usually depend on the patient's age, and the site and type of lesion. Due to the variability in the site of EDs, a wide range of presenting symptoms, such as respiratory distress, vague abdominal pain, abdominal mass, bleeding per rectum, intestinal obstruction and peritonitis, have been reported. ${ }^{(5)}$ Such nonspecific presentations are also why EDs may pose as a diagnostic challenge. In the present study, none of the patients were diagnosed antenatally. Some patients, however, had unusual symptoms - one patient presented with a nonhealing wound in the perineum that had previously been incised and drained due to suspicions of it being a perineal abscess, although a closer look at the surface would have revealed the presence of mucosa in the deeper part of the wound. Only one patient in our series had associated penoscrotal hypospadias. Such anomalies have been reported in up to $50 \%$ of patients, with vertebral defects being the most common. ${ }^{(1)}$

EDs may be cystic, tubular or mixed (cystic and/or tubular). Although EDs usually communicate with adjacent parts of the gut, instances of completely isolated duplication cysts have also been reported. ${ }^{(6)}$ We found various types of duplication cysts in our patients, including the cystic, tubular and complex mixed varieties. According to the literature, the ileum is the most common site of ED, whereas gastric and colonic duplications are rare, ${ }^{(4)}$ and thoracoabdominal duplications are the most challenging. ${ }^{(7-9)}$ In our series, the ileum was the most commonly involved site $(\mathrm{n}=5)$, presenting as either an isolated lesion or a combination. However, contrary to the literature, which does not describe a high incidence of rectal involvement, $(7,9,10)$ our series saw four cases (out of a total of nine) of rectal involvement. Also, there was a higher incidence of tubular ED $(n=5)$ in our study. Interestingly, one patient had a rare, complex duplication cyst that showed a combination of interconnected multiple tubular and cystic duplications (Fig. 1). Only a few instances of complex mixed cysts have been reported in the literature. ${ }^{(3)}$ In our patient, a long, tubular jejunoileal duplication, measuring $10 \mathrm{~cm}$, on the mesenteric side tapered into a patent cord, subsequently entering the ileal lumen. This part of the ileum, measuring $5 \mathrm{~cm}$, was thickened, oedematous and inflamed. From this portion of the gut, a cord-like continuation led to a $3 \mathrm{~cm} \times 3 \mathrm{~cm}$ cyst in the retroduodenal region, which was then connected to another cyst of approximately $3 \mathrm{~cm} \times 3 \mathrm{~cm}$ in the right hepatorenal area. The embryological origin of this type of cyst is difficult to explain.

Radiological visualisation of the split hypoechoic muscularis propria layer or identification of all four layers (mucosa, submucosa, muscularis propria and serosa) is considered diagnostic of duplications. As EDs are adjacent to the alimentary tract, the diagnostic criteria of ED include the presence of a common blood supply, and signs of double wall and enteric epithelial lining. ${ }^{(10)}$ Although ultrasonography is generally considered the cornerstone

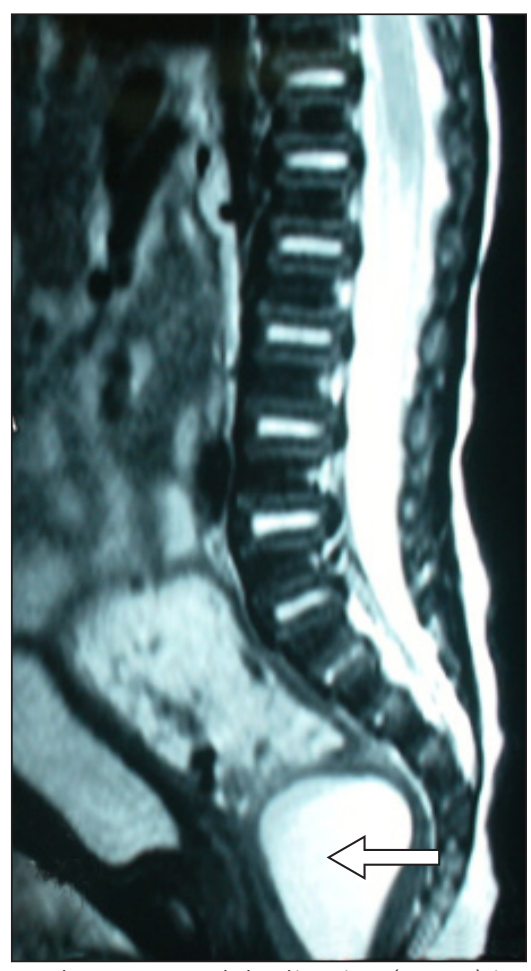

Fig. 2 MR image shows a rectal duplication (arrow) in a patient who presented with a perineal mass.

for the diagnosis of cystic duplications, ${ }^{(4)}$ it was not helpful in our series - only the patient with an ileal cyst was correctly diagnosed via ultrasonography. CT and MR imaging both play a major role in delineating the nature of the lesion, in relation to its adjacent structures. ${ }^{(11)}$ Diagnosis was suggested by CT and MR imaging in three of our patients. In the remaining patients, however, CT either showed the presence of dilated gut loops or suggested a differential diagnosis of mesenteric cysts or anterior sacral meningocele. MR imaging was able to differentiate the perineal abscess in one patient with underlying rectal duplication (Fig. 2). In three patients, in whom rectal bleeding was suggested on Meckel's scan, the diagnosis of ED was surprisingly accurate. This finding is significant, as other studies have also suggested Meckel's scan as a primary investigation tool in cases of suspected EDs. ${ }^{(5)}$

The surgical approach, with regard to the treatment of EDs, varies according to the site of the lesion. ${ }^{(12)}$ In our series, five patients were operated on using conventional upper transverse laparotomy incisions. In a patient with perineal mass and another with perineal abscess (Fig. 3), surgery was performed using chevron and cruciate incisions, respectively. The case of the patient with perineal abscess highlights the importance of considering ED in the differential diagnosis of children who present with chronic perineal sepsis. ${ }^{(13)}$

In all surgical procedures pertaining to ED cysts, it is essential to remove the cyst lining entirely. Marsupialisation is not advisable. ${ }^{(14)}$ However, in our study, marsupialisation had to be performed in one component of the complex cyst found in the patient with the complex duplication cyst, where it was closely attached to the subhepatic structures and duodenum. 


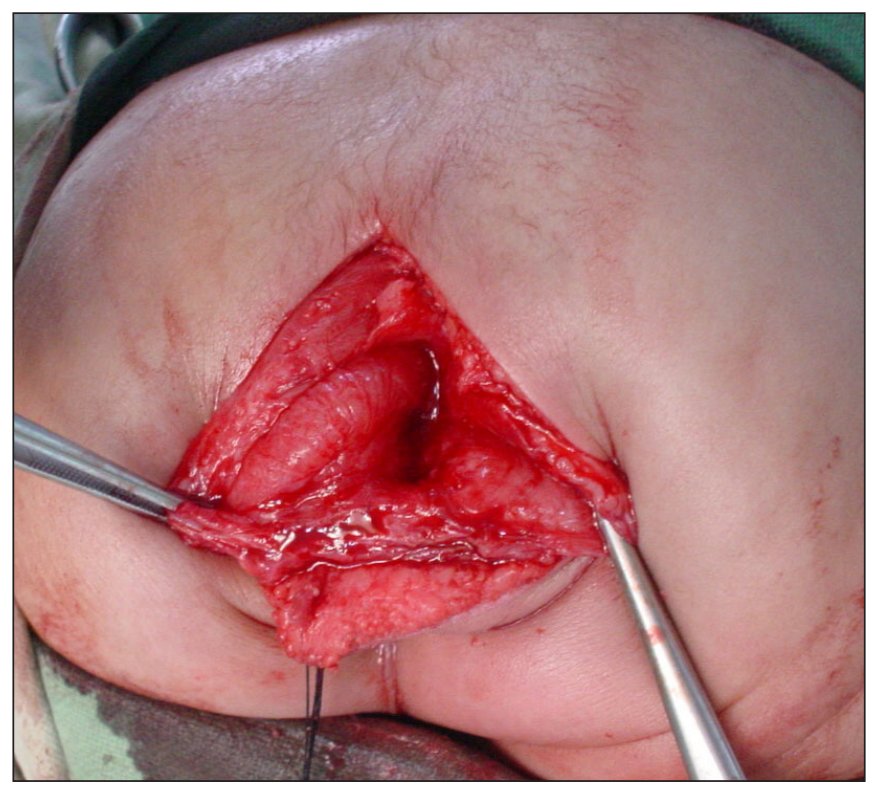

Fig. 3 Intraoperative photograph shows a rectal duplication, which presented as a perineal abscess.

Drainage procedures such as cystogastrostomy, cystoenterostomy and Roux-en-Y are only advisable when extensive resection is not possible due to a huge size, or close proximity to the common bile duct, portal vein or hepatic vessels. Partial resection, staged procedures or stripping of the mucosa should remain as viable options, especially in cases where the resection of large portions of the gut is not desired. ${ }^{(15)}$ Laparoscopic diagnosis and resection, while aesthetically acceptable and less invasive, require extensive experience. ${ }^{(16)}$ Although emergency surgical intervention due to intussusception, appendicitis, intestinal obstruction or volvulus has been previously reported in the literature, ${ }^{(8)}$ none of our patients required this.

Surgery was uncomplicated in all the patients enrolled in our study. Complications due to cysts that were large in size, closely attached to the mesenteric vessels or in communication with the vertebral canal have been reported. ${ }^{(4)}$ However, two of the patients in our study with rectal duplication developed superficial surgical wound infections. Additionally, one patient with rectal duplication developed a transient neurogenic bladder postoperatively. None of our patients reported longterm surgery-related complications or recurrence during a follow-up period of five years. In all our patients, the resected segment of the gut was sent for histopathological examination. Heterotopic gastric mucosa was found on histopathology in three patients who were initially diagnosed as having bleeding per rectum based on positive technetium-99m imaging. The incidence of $\mathrm{ED}$ in our study was comparable to other reports in the literature..$^{(5,8,17)}$ None of our patients had heterotopic pancreatic mucosa, contrary to a report by Sato et al. ${ }^{(18)}$
In conclusion, ED should be considered in the differential diagnosis of patients with unexplained abdominal symptoms and bleeding per rectum. In patients who present with rectal bleeding, a radioactive imaging for Meckel's diverticulum could help to diagnose potential duplications with ectopic gastric mucosa. As rectal duplications are common, they should be considered in children who present with chronic perineal sepsis. Prompt diagnosis, surgical treatment and a high index of suspicion can render an excellent outcome in patients with ED.

\section{REFERENCES}

1. Patel MP, Meisheri IV, Waingankar VS, et al. Duplication cyst of the pylorus- a rare cause of gastric outlet obstruction in the newborn. J Postgrad Med 1997; 43:43-5.

2. Lipsett J, Sparnon AL, Byard RW. Embryogenesis of enterocystomas-enteric duplication cysts of the tongue. Oral Surg Oral Med Oral Pathol 1993; 75:626-30.

3. Olajide AR, Yisau AA, Abdulraseed NA, et al. Gastrointestinal duplications: Experience in seven children and a review of the literature. Saudi J Gastroenterol 2010; 16:105-9.

4. Stringer MD, Spitz L, Abel R, et al. Management of alimentary tract duplication in children. Br J Surg 1995; 82:74-8.

5. Karnak I, Ocal T, Senocak ME, Tanyel FC, Büyükpamukçu N. Alimentary tract duplications in children: report of 26 years' experience. Turk J Pediatr 2000; 42:118-25.

6. Okamoto T, Takamizawa S, Yokoi A, Satoh S, Nishijima E. Completely isolated alimentary tract duplication in a neonate. Pediatr Surg Int 2008; 24:1145-7.

7. Ildstad ST, Tollerud DJ, Weiss RG, et al. Duplications of the alimentary tract. Clinical characteristics, preferred treatment, and associated malformations. Ann Surg 1988; 208:184-9.

8. Schalamon J, Schleef J, Höllwarth ME. Experience with gastro-intestinal duplications in childhood. Langenbecks Arch Surg 2000; 385:402-5.

9. Ijaz L, Husnain M, Malik SI, Mirza B. Cecal duplication cyst presenting as acute intestinal obstruction in a neonate. APSP J Case Rep 2011; 2:11.

10. Cheng G, Soboleski D, Daneman A, Poenaru D, Hurlbut D. Sonographic pitfalls in the diagnosis of enteric duplication cysts. AJR Am J Roentgenol 2005; 184:521-5.

11. Gümüş $M$, Kapan $M$, Gümüş $H$, Onder A, Girgin S. Unusual noncommunicating isolated enteric duplication cyst in adults. Gastroenterol Res Pract 2011; 2011:323919.

12. Holcomb GW 3rd, Gheissari A, O'Neill JA Jr, Shorter NA, Bishop HC. Surgical management of alimentary tract duplications. Ann Surg 1989; 209:167-74.

13. Iyer CP, Mahour GH. Duplications of the alimentary tract in infants and children. J Pediatr Surg 1995; 30:1267-70.

14. Ravitch MM. Duplications of the gastrointestinal tract. In: Welch KJ, Randolph JG, Ravitch MM, Mustard WT, eds. Pediatric Surgery, 4th ed. Chicago: Years book publishers, 1986; 914-5.

15. Wrenn EL. Alimentary tract duplications. In: Ashcraft KW, Holder TM, eds. Pediatric Surgery, 2nd ed. Philadelphia: WB Saunders Company, 1993; 421-34.

16. Sasaki T, Shimura H, Ryu S, Matsuo K, Ikeda S . Laparoscopic treatment of a gastric duplication cyst: report of a case. Int Surg 2003; 88:68-71.

17. Yang MC, Duh YC, Lai HS, et al. Alimentary tract duplications. J Formos Med Assoc 1996; 95:406-9.

18. Sato T, Oyamada M, Chiba $H$, et al. Ileal duplication cyst associated with heterotopic pancreas: report of a case and literature review. Acta Pathol Jpn 1993; 43:597-602. 